Alonso-Sanz, Amparo.

Profesora de la Universitat de València. Instituto Universitario de Creatividad e Innovaciones

Educativas. Grupo CREARI.

\title{
Así nos movemos en el aula, así nos vemos representados, así lo visibilizamos artísticamente.
}

\section{This is how we move about in our classroom; this is how we view ourselves represented; this is how we artistically visualise it.}

TIPO DE TRABAJO:

Comunicación.

PALABRAS CLAVE:

Calidad estética, Investigación Educativa Basada en las Artes, escuela, voz infantile.

KEY WORDS:

Aesthetic quality, Visual Arts Based Educational Research, school, children voice

RESUMEN.

La propuesta forma parte del proyecto de investigación "Estudio de la calidad estética de tres centros educativos" ${ }^{1}$ en el que observamos la forma en que la arquitectura, la cultura visual y la estética cotidiana configuran un entramado que da cobertura a las condiciones de calidad en las que se desarrollan los procesos de enseñanza aprendizaje. La experiencia estética se contempla como forma de experimentar la cotidianeidad de la escuela desde la relación entre el cuerpo y el entorno.

El estudio se desarrolla durante 2016 en tres escuelas de la ciudad de Alicante escogidas por representar realidades diversas como un centro urbano multicultural, un centro urbano de etnia gitana, y un centro rural con feriantes. Con la participación de un total de 309 estudiantes.

El objetivo de esta investigación consiste en conocer la forma de relacionarse de los escolares con el espacio educativo y con los elementos que lo constituyen. Y pretende visibilizar la relación entre cuerpo y espacio escolar a través de Metodologías de Investigación Educativa Basadas en Artes Visuales. La fotografía es el instrumento de recogida de datos que permite obtener las opiniones de los escolares. Los resultados muestran representaciones de la corporalidad de los aprendices en las aulas, pasillos, patios... a través del uso de planos en planta y muñecos con los que se identifican. Se visualiza dónde y cómo se realizan las distintas tareas que suceden en la escuela, de qué manera el cuerpo se relaciona con el espacio y los elementos que lo constituyen para: relajarse, almorzar, jugar solo, jugar en equipos, caminar, escuchar, aprender, trabajar en grupo, exponer. Las conclusiones nos permiten relacionar factores estéticos de la escuela con el comportamiento y movimiento corporal del discente.

${ }^{1}$ INV_AE15_332576, financiado por el Vicerrectorado de Investigación y Política Científica la Universidad de Valencia. 


\section{ABSTRACT}

This study forms part of the project titled: "Aesthetic Quality Research of Three Valencian Schools". Through it, one may perceive how the architecture, visual culture and daily aesthetics constitute a network that encompasses the conditions for a quality teaching-learning process. Therefore, the aesthetic experience is presented in a way to explore the daily school routine from an interactive perspective between one's body and their environment.

This research took place during 2016 at three schools located in Alicante (Spain). Those schools were chosen as being representative of diverse situations: a multicultural urban school; a gypsy-ethnic background urban school; and a transient-populated rural school. Overall, 309 students were included in this research.

The objective of this research is to understand how the students relate to the educational environment and its elements. Additionally, this research aims to visualize the relation between one's body and their environment, applying Educational Research Based on Visual Arts. Photographs are the means in which data is collected, subsequently conveying the students' opinions. The results of this study transmit representations of the students' embodiment in the classrooms, hallways, playgrounds, and so forth, expressed through the displayed drawings of floor plans and human figures in which the students identify themselves. Therefore, how and where the different tasks performed at schools are visualised, along with how one's body relates to its surroundings and the surrounding elements. In summary, how the children relax, snack, play alone, play in teams, walk, listen, learn, work with peers, and address the classroom. The results will allow us to interrelate the school's aesthetic aspects with the students' behaviour and their physical movements.

\section{CONTENIDO.}

Introducción.

La estética cotidiana (Saito, 2007; Mandoki, 1994, 2006; Light y Smith, 2005) es un concepto relacionado con la experiencia estética en el día a día y la apreciación del orden, la belleza, la limpieza o sus opuestos. Aquella experiencia que en vez de producirse en los entornos culturales como museos, galerías de arte o vinculada a las artes y la filosofía, tiene más que ver con lo recreativo, ordinario, o incluso con actos triviales.

Según Errázuriz-Larraín (2015) la estética cotidiana escolar se caracteriza porque: [1] permite defender perspectivas estético-visuales que guarden coherencia con los proyectos educativos desarrollados en las escuelas; [2] es complejo generar espacios educativos estéticamente consistentes que comuniquen a través del entorno los valores que deseamos experimenten los niños y niñas en su interior; [3] el fenómeno estético es cotidiano, relativo a las rutinas diarias y no tiene que ver solamente con lo extraordinario; [4] desde la perspectiva prosaica de Mandoki centra la atención en la experiencia estética del sujeto en relación con su entorno.

Nos interesa recoger la percepción estética del alumnado, la forma en que se relacionan con su espacio educativo y con los elementos que lo constituye. Es por ello que la metodología seguida debe aproximarse a las capacidades comunicativas de cada población. Los participantes menores, de cursos de primaria, pueden encontrar en el lenguaje visual una vía de comunicación complementaria a la verbal que no podemos descuidar. A partir de creaciones artísticas del alumnado, es posible recoger las opiniones e inquietudes del colectivo estudiantil con referencia al espacio educativo que les rodea. Con este estudio ofrecemos la posibilidad de recrear artísticamente situaciones cotidianas, con la representación tridimensional como medio de comunicación alternativo al verbal. De este modo la estética escolar cotidiana se transfiere plásticamente. Para ello les ofrecemos planos de arquitectura de sus colegios sobre los que interactuar con muñecos Playmobil. Estos dos elementos ya han sido utilizados artísticamente con anterioridad y mostramos a continuación algunos ejemplos.

Según Yávar (2013) Isabel Geisse "trabaja a partir de planos de arquitectura que toma como elemento de representación gráfica con función de pauta estructural y a partir del desarrollo e investigación de su propia técnica productiva, [...] busca apropiarse de los planos a partir de su propia interpretación" y además "comunica a través de su trabajo la necesidad de volver a habitar con identidad el espacio que nos rodea, al apropiarnos de nuestro entorno" 

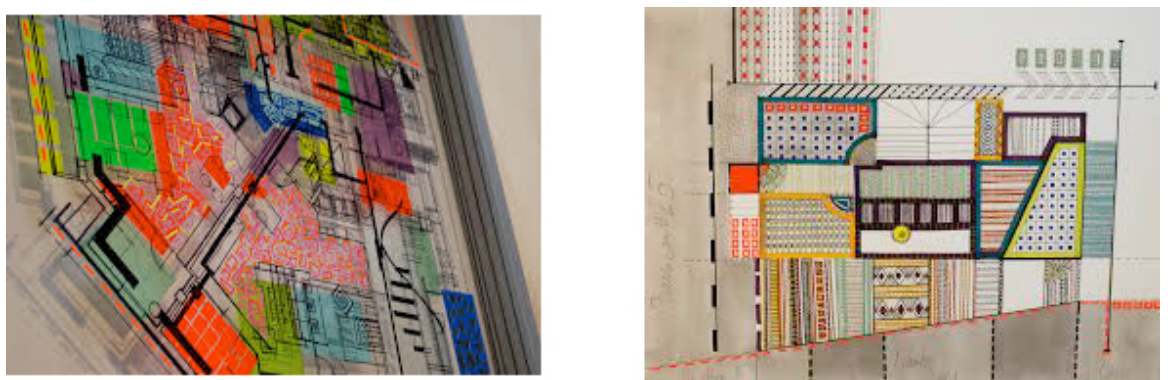

Ilustración 1. Citas visuales fragmento de Isabel Geisse ${ }^{2}$

Por otro lado el artista Jorge Villalba demuestra que a pesar de la reducida movilidad de los muñecos Playmobil, es posible recrear situaciones compositivamente complejas y en las que se produzca la interacción entre un elevado número de personajes.

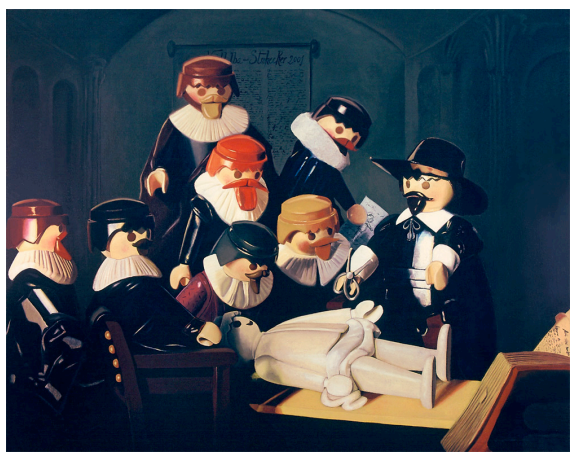

Ilustración 2. Cita visual literal de Jorge Villalba “Die anatomie des Dr. Tulp"3

Además nos basamos en el proceso creativo del fotógrafo Cayetano Ferrández. El artista procede al registro fotográfico, después de la construcción de escenografías, y el mensaje se construye a partir de la interacción de muñecos con un entorno artificial construido. Además como él mismo afirma el juego previo tiene mucho interés en la elaboración de las piezas y "los muñecos siguen siendo ese pequeño ejército de actores que de una manera genérica representan la condición humana” (Ferrández, 2017).
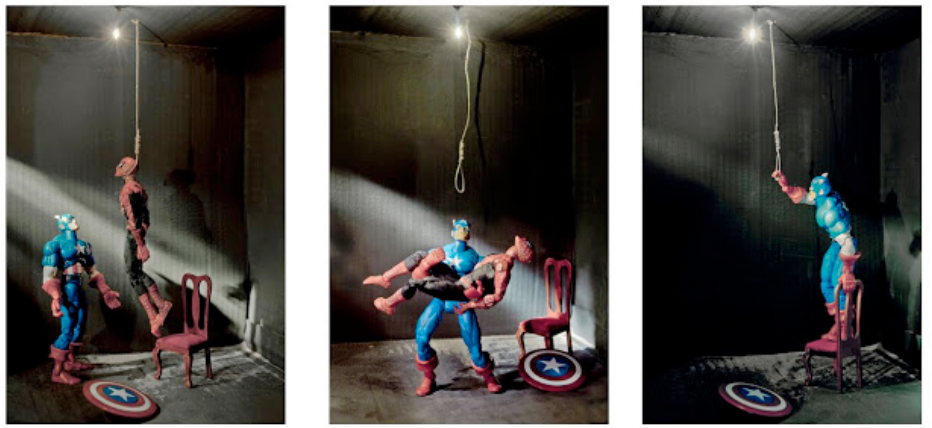

Ilustración 3. Cita visual literal de Cayetano Ferrández (2017) "El suicidio de Spiderman" (2010) de la serie Crymen, tríptico $112,50 \times 75 \mathrm{cn} / \mathrm{u}^{4}$

\footnotetext{
${ }^{2}$ Obtenida de http://www.plataformaarquitectura.cl/cl/02-317938/arte-y-arquitectura-reinterpretacion-de-planos-arquitectonicos-por-isabelgeisse

${ }_{3}^{3}$ Obtenida de http://www.jorge-villalba.com/

${ }^{4}$ Obtenida de http://www.cayetanoferrandez.com/
} 
Se procede dividiendo cada clase de participantes en tres equipos de trabajo. Se sitúan tres planos de las distintas zonas que conforman su escuela distribuidos por el aula. Se pide a cada equipo que se sitúe entorno a uno de los planos para responder sobre él a tres preguntas. Luego el alumnado rota a otro plano para responder a otras tres preguntas. Y por último rotan por tercera vez para colocarse alrededor del tercer plano y responder a otras tres preguntas. Las cuestiones son en qué lugar de la escuela y cómo se mueven para realizar las siguientes tareas: almorzar, aprender, caminar, escuchar, exponer, jugar en equipos, jugar solos, relajarse y trabajar en equipo. La forma de responder a estas 9 cuestiones de investigación no es mediante el lenguaje verbal, sino a través del lenguaje simbólico que ofrece el arte. El alumnado responde situando sobre el plano diferentes muñequitos que les representan a ellos mismos, pues cada estudiante utiliza un monigote con el que se siente identificado. La representación en el espacio del plano con personajes es una metáfora de su comportamiento en la escuela. Tratan de reflexionar sobre los comportamientos que tienen en los diferentes lugares escolares, pero también respecto a cómo se relaciona su cuerpo con el espacio y con los pares. Es decir, mediante el diálogo y consenso al que llega cada equipo conversando, piensan y discuten cómo son sus conductas más habituales.

La fotografía es el instrumento de recogida de datos, actúa como herramienta de registro final de las escenas recreadas. Esta permite obtener las opiniones del grupo escolar, imágenes que ellos mismos toman con la cámara. Para ello previamente les damos algunas nociones básicas de fotografía a todos ellos. Les explicamos conceptos como el encuadre o la angulación y que el modo en que ellos fotografíen transmitirá unas sensaciones u otras al espectador.

Desarrollo.

Apostando por una epistemología etnológica de la observación, valoramos el contacto efectivo con los interlocutores, la representatividad cualitativa del grupo elegido (situando desde esta perspectiva conceptos como el de etnia), la capacidad de generalización (desde la exploración de un caso singular que remite a la elaboración de configuraciones que exceden ampliamente ese único caso), la legitimidad de la antropología de la contemporaneidad cercana, y la alteridad íntima (Auge, 2000, pp. 20-26).

La población con la que se desarrolla el trabajo es el alumnado de Educación Primaria (de entre 6 y 12 años) de 3 escuelas a las que nos referiremos como: CEIP CF, CEIP JCA y CEIP MLS. Este conjunto se caracteriza por su carácter plurisocial -en tanto albergan diversos grupos socio-económicos culturales-: una escuela rural de población española y feriantes, una escuela urbana multicultural, una escuela urbana de etnia gitana. Con la participación de un total de 309 estudiantes.

El objetivo de esta investigación consiste en conocer la forma de relacionarse de los escolares con el espacio educativo y con los elementos que lo constituyen.

La elección metodológica que se propone es la Investigación Educativa Basadas en Artes Visuales (Marín, 2005; Marín y Roldán, 2008, $2009,2010)$ a partir de creaciones artísticas del alumnado para recoger sus opiniones e inquietudes con referencia al espacio educativo que les rodea (Burke, et. al, 2006).

Las imágenes recogidas se estudian conforme a las tres escuelas. Por otro lado se clasifican en columnas según los cursos que participan. Y se clasifican en filas, siguiendo las categorías temáticas correspondientes a cada pregunta que se les formula: almorzar, aprender y caminar, escuchar, exponer y jugar en equipos, jugar solos, relajarse y trabajar en equipos. Esto nos permite elaborar estas tablas de figuras que visibilizan la cantidad de imágenes que produce el alumnado para comunicar sus pensamientos.

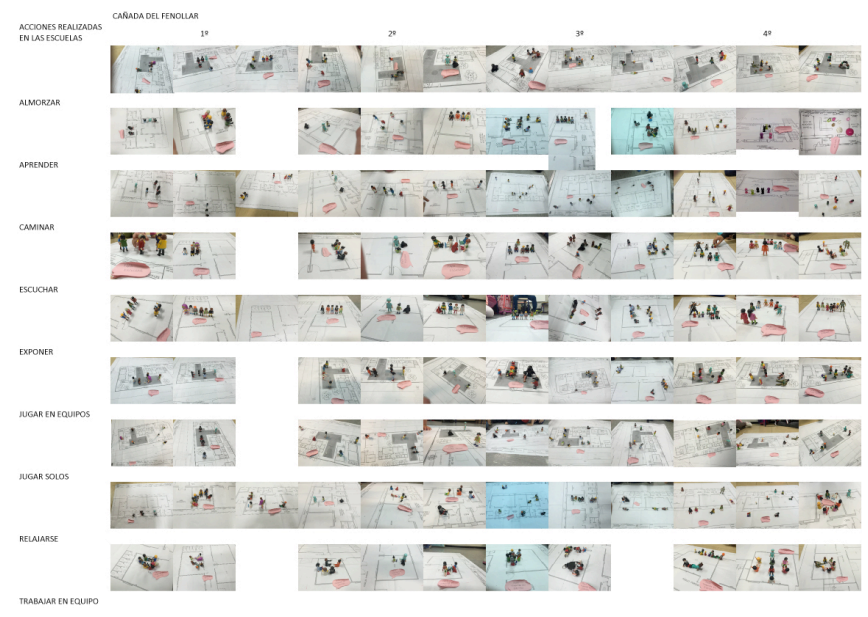

Ilustración 4. Conjunto de respuestas del alumnado del CEIP CF. 


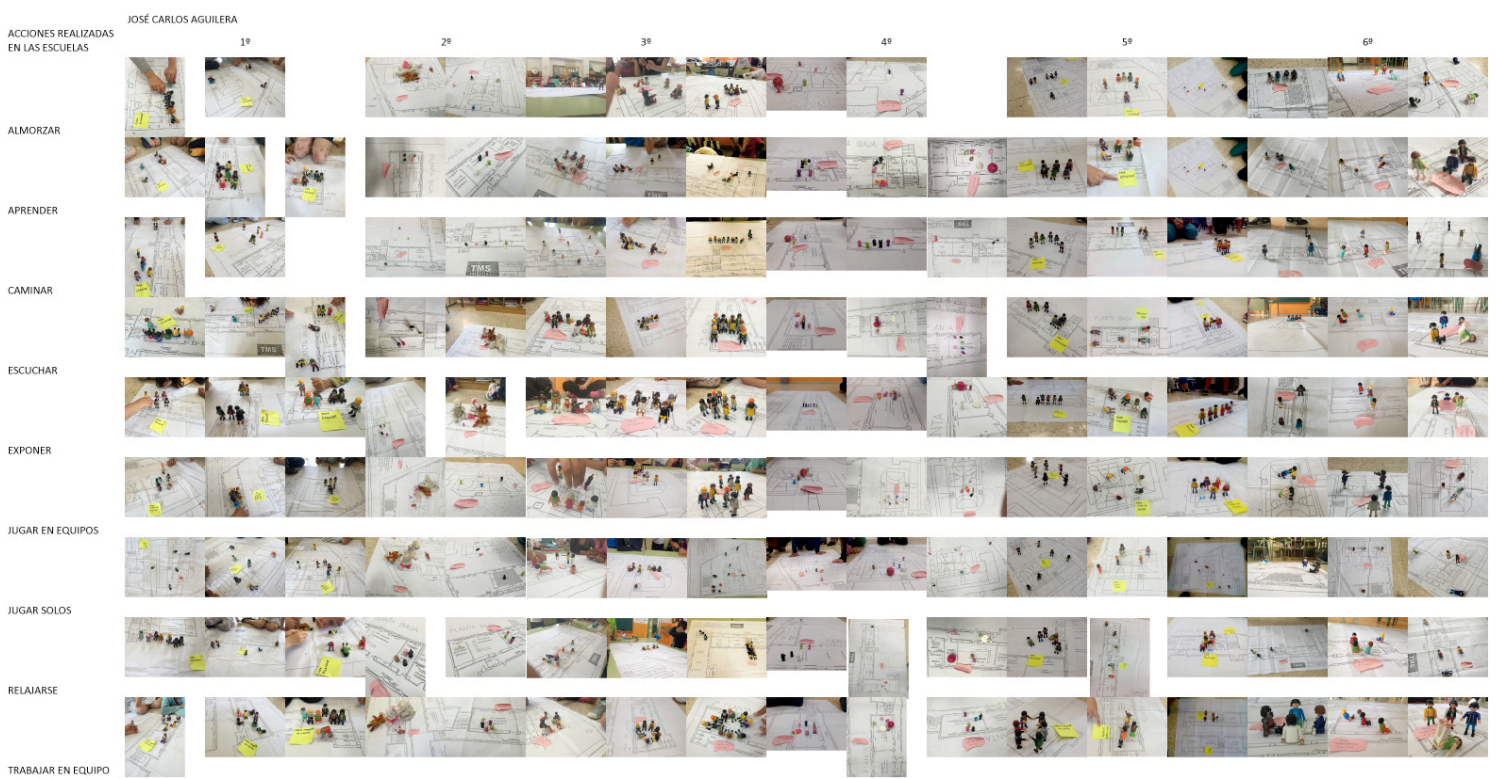

Ilustración 5. Conjunto de respuestas del alumnado del CEIP JCA.

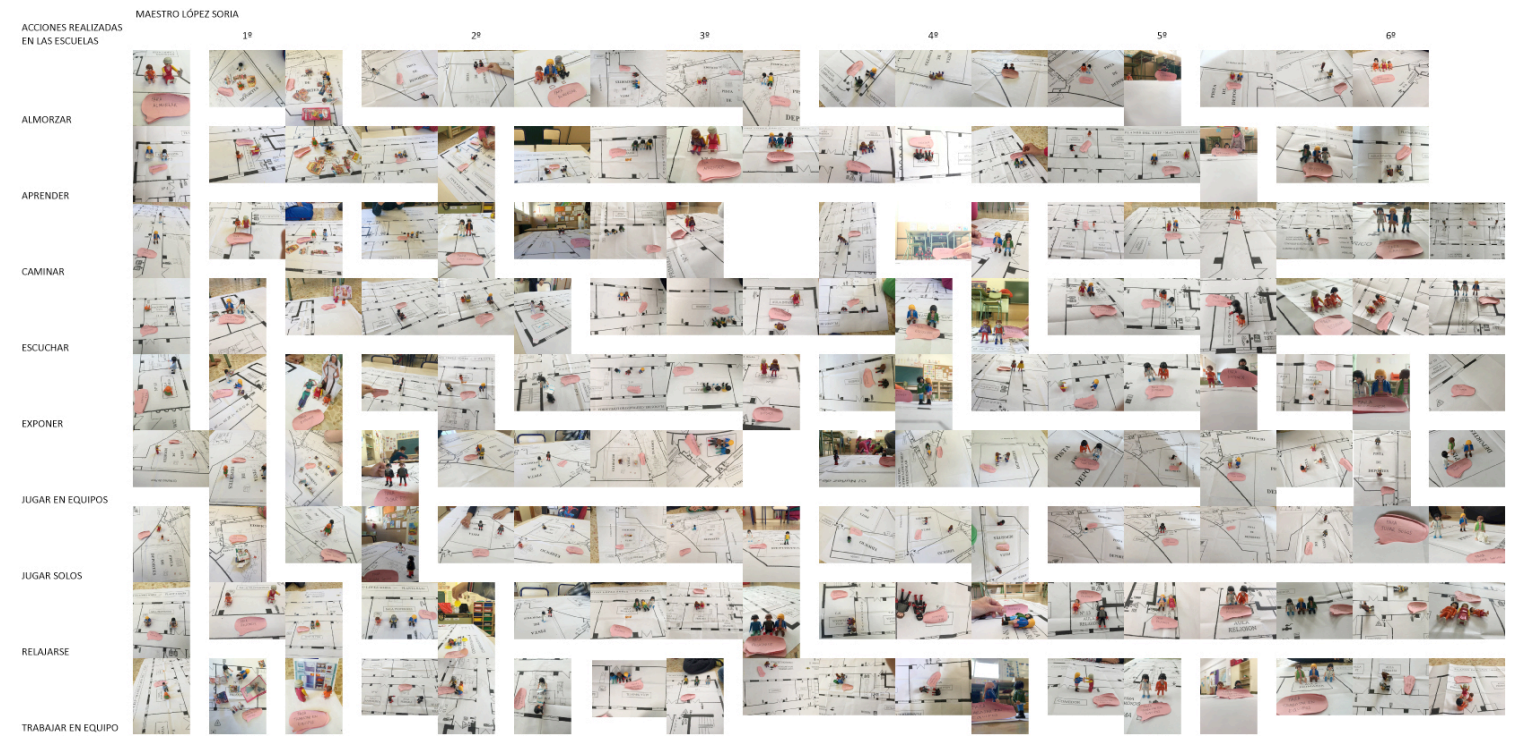

Ilustración 6. Conjunto de respuestas del alumnado del CEIP MLS.

El análisis se centra en observar las propiedades estilísticas, compositivas y expresivas, empleadas desde el punto de vista artístico por el alumnado. Esto nos permite valorar la validez de estos métodos visuales de investigación. Y a su vez el análisis permite indagar en los factores estéticos de la escuela en relación con el comportamiento y movimiento corporal del discente.

Al observar el conjunto de imágenes creadas como respuestas a las posibles acciones que se desarrollan en el colegio, percibimos que ámbitos como los almacenes, la conserjería o la cocina, nunca son utilizados en las contestaciones. Y otros espacios como los baños, la dirección, las zonas de paso o las aulas específicas aparecen en menor medida. La mayor parte del tiempo se pasa en aulas y patio, lo cual tiene un claro reflejo en este estudio. Esto debe hacernos reflexionar no solo sobre la necesidad de dedicar más recursos a la mejora estética de estos entornos, sino precisamente al contrario, comenzar a mirar con una mirada pedagógica otros lugares menos explotados. 
A través de series muestra ofrecemos una selección de ejemplos por ser representativos de las principales concepciones detectadas entre las respuestas visuales del alumnado.
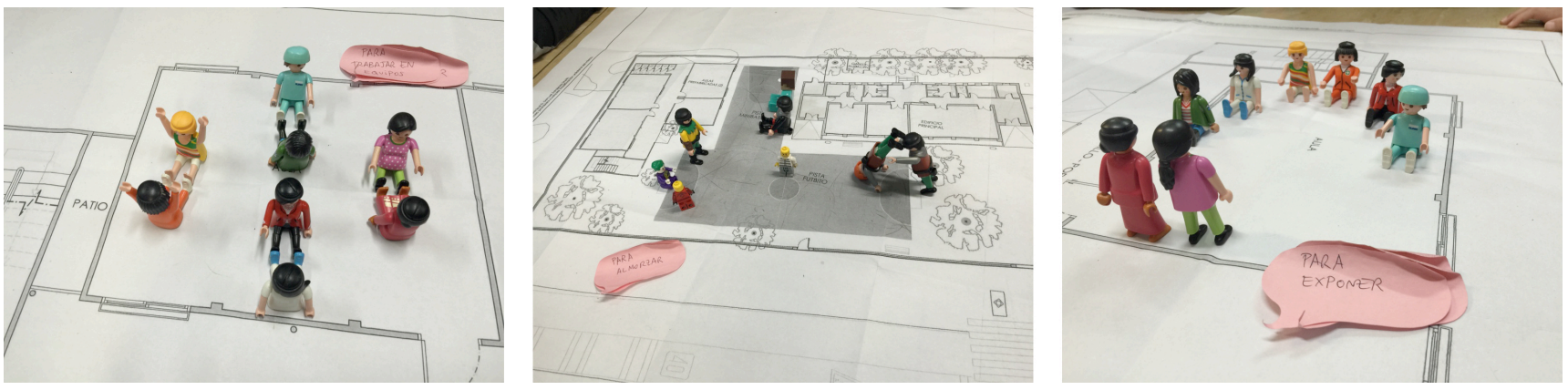

Ilustración 7. Serie muestra. Ejemplo de respuestas visuales del alumnado de 40 curso del CEIP CF a las preguntas: ¿Cómo juegas en equipos en el colegio? ¿Dónde y cómo almuerzas? ¿Dónde y cómo expones trabajos escolares?

El cuidado con que se sitúan los muñecos, demuestra la implicación del alumnado al ofrecer sus respuestas. Manifestando que no son disposiciones aleatorias o fruto del juego, sino de la reflexión y decisión consensuada entre compañeros. Las extremidades de los monigotes son movidas para expresar con mayor claridad el tipo de acción que desarrollan, a pesar de la reducida movilidad que permiten este tipo de muñecos. La interacción entre personajes permite observar acciones compartidas. La disposición en el espacio visibiliza que el alumnado comprende perfectamente la representación espacial que se hace con los planos arquitectónicos; comprenden qué líneas equivalen a tabiquería, qué dibujos semejan los árboles del patio...
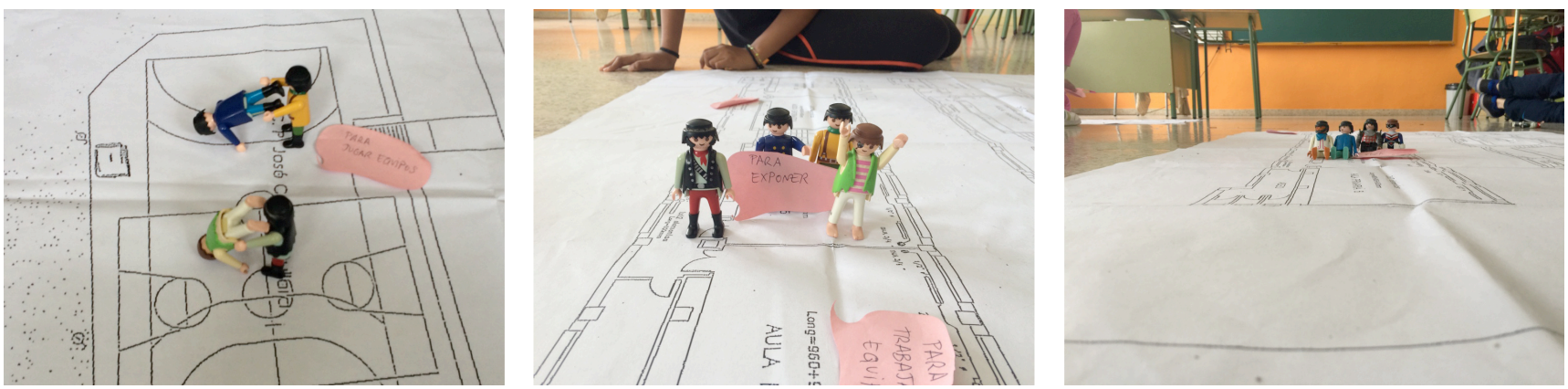

Ilustración 8. Serie muestra. Ejemplo de respuestas visuales del alumnado de 6o curso del CEIP JCA a las preguntas: ¿Cómo juegas en equipos en el colegio? ¿Dónde y cómo expones trabajos escolares? ¿Cómo y en qué lugar de la escuela escuchas?

La expresión gráfica bidimensional, junto con la representación tridimensional (que permite el uso de muñecos), se conjugan aquí para dar cuenta de los usos y costumbres del alumnado. El colectivo estudiantil es capaz de identificarse de forma simbólica y abstracta con planos arquitectónicos y muñecos que deben entenderse desde la perspectiva escultórica. El conjunto funciona a modo de maqueta de la realidad escolar, y permite mostrar las relaciones entre cuerpo y espacio en el entorno educativo.

La escala, como concepto a incorporar en sus conocimientos artísticos, es empleada aquí por los menores de forma intuitiva y versátil. La escala es también un recurso empleado por artistas que han incorporado las arquitecturas a su producción: "Daniel Chust Peters, en Cielo mío, reproduce su taller convirtiéndolo en un juguete con valor de uso directo. Carlos Bunga continúa con el juego de la escala reducida y registra en vídeo su manipulación de pequeñas construcciones precarias, cuestionando la rigidez de la arquitectura convencional" (Goyarrola e Ínsua, 2016, p. 2) 

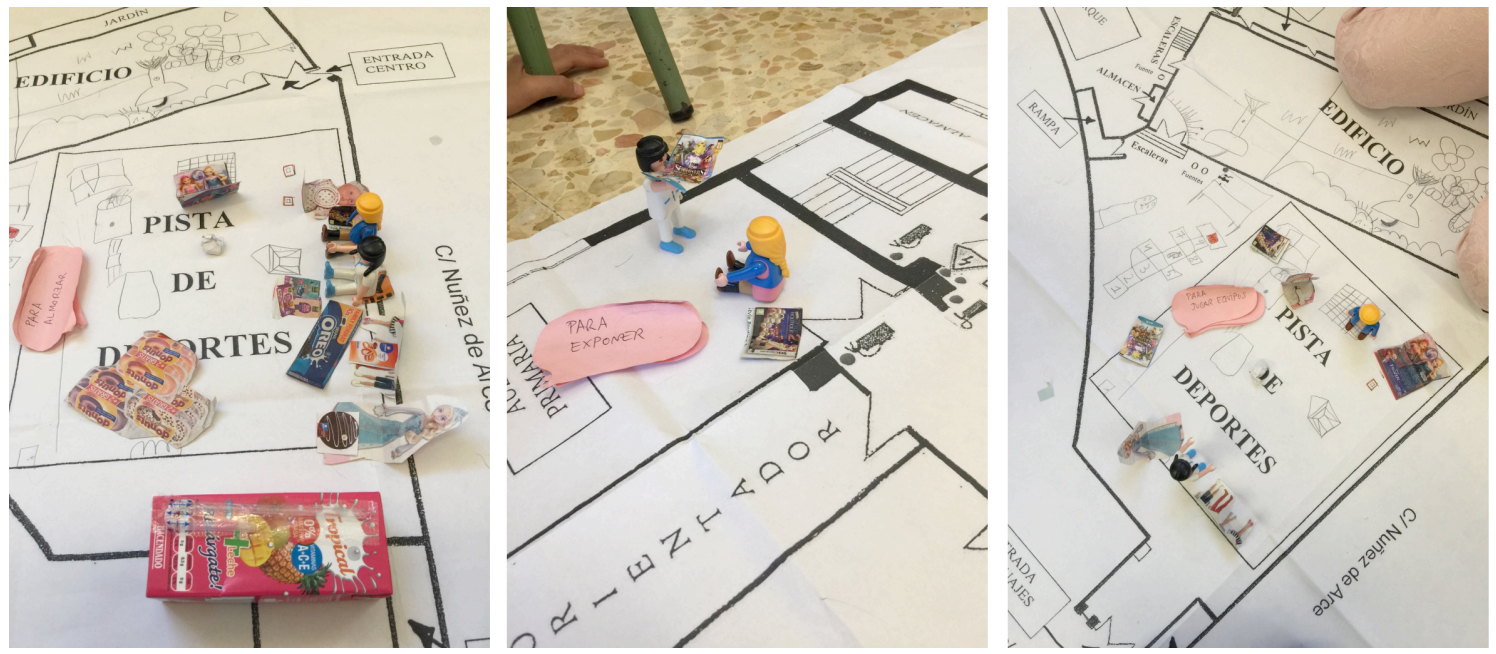

Ilustración 9. Serie muestra. Ejemplo de respuestas visuales del alumnado de 10 curso del CEIP MLS a las preguntas: ¿Dónde y cómo almuerzas? ¿Dónde y cómo expones trabajos escolares? ¿Cómo juegas en equipos en el colegio?

Parte del alumnado encuentra limitante la forma en que la arquitectura tradicional representa su realidad. Manifiestan la necesidad de intervenir los planos y disfrutan completando las vistas en planta con dibujos que añaden información no representada en las fotocopias. Así, en el patio añaden la rayuela que tienen pintada en el suelo, en las aulas dibujan mesas y sillas, y en la azotea del edificio proyectan sus deseos de una cubierta ajardinada con uso lúdico.

Además, el uso de unos pocos muñecos tampoco es suficiente para comunicar sus pensamientos. Haciendo alarde de una gran creatividad, deciden recortar siluetas en revistas publicitarias y hacer uso de estos fragmentos de papel a modo de collage. Representan así los productos que habitualmente almuerzan en el patio como zumos y bollería, los libros que usan en el aula, u otras compañeras de clase a modo de personajes de Walt Disney. Participan de la entrevista con entusiasmo, diversión y alto grado de motivación durante los 45 minutos que dura la sesión, a pesar de ser la población de un Centro de Acción Educativa Singular (CAES) que habitualmente muestra escasa atención sostenida.

Ninguna de estas dos iniciativas ha sido motivada por el profesorado o el equipo investigador. Simplemente ante la libertad expresiva han hallado el modo de solventar problemas expresivos de forma creativa.
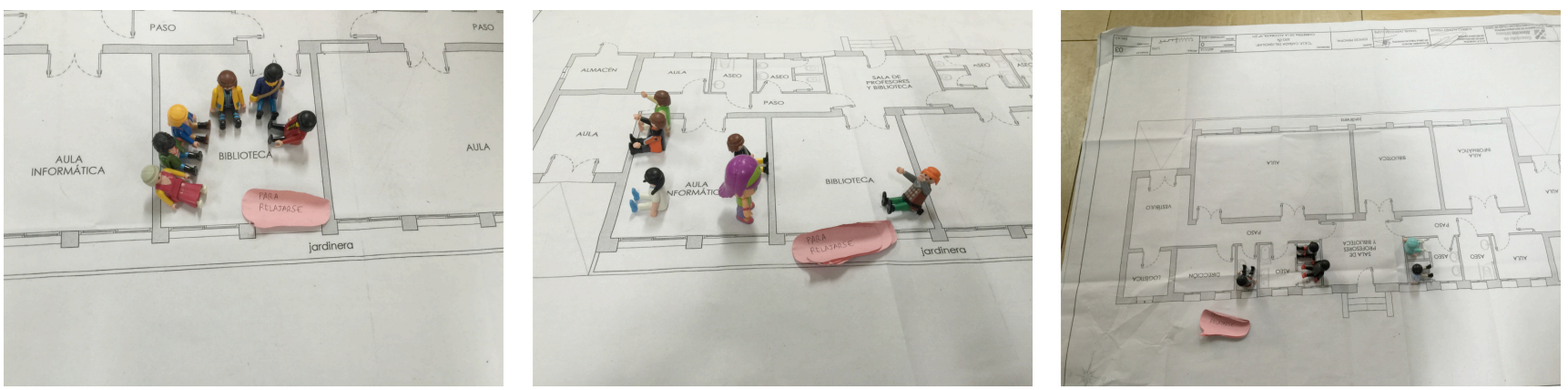

Ilustración 10. Serie muestra. Ejemplo de respuestas visuales del alumnado de 10 curso del CEIP CF a la pregunta: ¿Dónde y cómo te relajas? 
Frente a una misma cuestión de investigación las respuestas obtenidas dan resultados diversos e imprevisibles, incluso dentro de una misma aula. Así ocurre con el lugar escogido por el alumnado para relajarse. Mientras un equipo considera que las asambleas que realizan en la biblioteca donde comparten historias les relaja mucho, otros consideran que el visionado de imágenes en la sala de informática es la mejor opción, frente a otros que se sitúan en los baños para hallar la calma, intimidad y tranquilidad precisa para relajarse. Esto demuestra que las respuestas no son copiadas entre grupos (la metodología de trabajo por rotación tampoco favorece que sepan lo que han respondido otros) sino que son fruto de sus vivencias.

La experiencia estética escolar cotidiana es diversa y a mayor versatilidad del entorno educativo mayores posibilidades de experimentación ofrece a quienes lo habitan. Por ello debemos fomentar los espacios versátiles, pero también sensorialmente estimulantes.


\section{Ilustración 11. Serie muestra. Ejemplo de respuestas visuales del alumnado de 4 curso del CEIP MLS a las preguntas: ¿Dónde y cómo almuerzas? ¿Por dónde y cómo caminas? ¿Cómo y en qué lugar de la escuela escuchas?}

Entre las diferentes respuestas observamos que el alumnado emplea recursos fotográficos para hacer énfasis en los aspectos expresivos que les interesan. Así para comunicar el modo en el que se almuerza se emplea por ejemplo un contrapicado porque facilita ver la acción frente al lugar en el que se desarrolla; para expresar la acción de caminar se utiliza una angulación normal que visibiliza todo el contexto escolar además de los personajes y transmite una idea de cotidianeidad; mientras que para dejar constancia de la actividad de escucha que tiene lugar en la dirección del centro se hace uso del picado con el que los sujetos amonestados todavía parecen más empequeñecidos y sometidos.

Se demuestra que es posible introducir con éxito en las aulas de primaria, sin esperar a edades posteriores, otros aprendizajes menos tradicionales vinculados a las artes. Estas enseñanzas artísticas pueden ser: (1) la representación espacial mediante simbología, el dibujo y la expresión gráfica que ofrecen los planos arquitectónicos; (2) la metáfora a través de elementos cotidianos, como pueden ser los juguetes; (3) la fotografía a través de teléfonos móviles; (4) la producción artística compartida, en lugar del trabajo individual; (4) la expresión de pensamientos y constructos visuales a través del lenguaje plástico.

Las artes ofrecen métodos visuales de investigación cada vez más empleados por la comunidad científica. Con este estudio se ha corroborado la validez de las herramientas de entrevista mediante lenguaje artístico, en lugar de las tradicionales entrevistas mediante lenguaje verbal. Además se ha demostrado que el lenguaje artístico es de gran utilidad con poblaciones de estudio infantiles por diversos motivos: (1) reemplaza las deficiencias de un lenguaje verbal todavía por desarrollar a tempranas edades, (2) el carácter lúdico del arte motiva una participación prolongada, activa y sostenida en el tiempo, (3) permite recoger respuestas emergentes y no previsibles por el investigador -lo cual es típico también de los métodos cualitativos-, (4) permite recoger respuestas de carácter simbólico o metafórico -característico de los métodos artísticos-.

El colegio es un lugar de socialización donde se educa a los cuerpos a regirse por leyes. Las relaciones entre sujetos, así como las relaciones entre éstos y el espacio escolar, se producen mediadas por toda una normatividad que estructura los comportamientos y movimientos permitidos frente a los prohibidos. 


\section{FUENTES REFERENCIALES.}

AUGE, M. 2000. Los "no lugares" espacios del anonimato. Una antropología de la Sobremodernidad. (Edic. orig. en francés, 1992). Barcelona: Gedisa.

BURKE, C., GALLAGHER, C., PROSSER, J., Y TORRINGTON, J. 2006. The view of the child: Explorations of the visual culture of the made environment. En Economic and Social Science Research Council (ESRC) Conference on Pupil Voice, Nottingham, UK.

ERRÁZURIZ-LARRAÍN, L. H. 2015. Calidad estética del entorno escolar: el (f)actor invisible. Arte, Individuo y Sociedad, 27(1), 81-100. http://dx.doi.org/10.5209/rev_ARIS.2015.v27.n1.43861

FERRÁNDEZ, C. 27 de enero de 2017. Sé que los coleccionas, ¿te han dado mucho juego tus muñecos articulados? http://www.cayetanoferrandez.com/

GOYARROLA, E., E ÍNSUA, X. 2016. Alt-architecture. En Tríptico de Comisariat: Nuevas miradas sobre la Colección "la Caixa".

LIGHT A. Y SMITH J. 2005. The Aesthetic of Every Day Life. Columbia: University Press.

MANDOKI, K. 1994. Prosaica, Introducción a la Estética de lo Cotidiano. México: Editorial Grijalbo.

MANDOKI, K. 2006. Estética Cotidiana y Juegos de la Cultura. México: Siglo XXI Editores.

MARíN, R. 2005. La “Investigación Educativa Basada en las Artes Visuales” o “Arteinvestigación educativa”. En R. Marín (Ed.), Investigación en Educación Artística (pp. 223-274). Granada: Editorial Universidad de Granada.

MARÍN, R. Y ROLDÁN, J. 2008. Imágenes de las miradas en el museo. Un fotoensayo descriptivo- interpretativo a partir de H. Daumier. En R. de la Calle y R. Huerta (Eds.), Mentes Sensibles. Investigar en Educación y Museos. (pp. 97-108). València: Publicacions de la Universitat de.

MARÍN, R. Y ROLDÁN, J. 2009. Proyecciones, tatuajes y otras intervenciones en las obras del museo (Un fotoensayo a partir de T. Struth). Arte, Individuo y Sociedad, 21, 99-106.

MARÍN, R. Y ROLDÁN, J. 2010. Photo essays and photographs in visual arts-based educational research. International Journal of Education through Art, 6 (1), 7-23.

SAITO, Y. 2007. Everyday Aesthetic . Oxford University Press.

YÁVAR, J. 13 Diciembre, 2013. Arte y Arquitectura: Reinterpretación de planos arquitectónicos por Isabel Geisse. Disponible en http://www.plataformaarquitectura.cl/cl/02-317938/arte-y-arquitectura-reinterpretacion-de-planos-arquitectonicos-por-isabel-geisse 